\title{
For the Patient
}

The full report is titled: "Effect of chemical modifications on allergenic potency of peanut proteins". It is in the May-June 2015 issue of Allergy Asthma Proceedings (volume 36, pages 185 to 191). The authors are Ramon Bencharitiwong, Hanneke PM van der Kleij, Stef J Koppelman and Anna Nowak-Weegrzyn.

For the Patient is provided to physicians so that the patients can better understand the language of modern medicine.

For the Patient is written by the editors (Bellanti, JA and Settipane, RA) and provided to practitioners so that patients can better understand the usefulness of new information resulting from medical research.

For the Patient is intended for informational purposes only. This educational synopsis is not meant as a substitute for medical advice. If you have questions regarding this material or are in need of medical advice, please contact your physician. Reproduction is limited to notfor-profit educational purposes only. All other reproductions must be approved by OceanSide Publications.

\section{A vaccine for peanut allergy?}

Peanut allergy is the major cause of severe and fatal food-induced allergic reactions in the US. It develops in genetically susceptible individuals in whom exposure to peanut protein results in an immune response characterized by the production of $\operatorname{IgE}$ (allergic) antibody directed at the peanut protein. Once a person has become allergic to peanut, subsequent exposures result in the symptoms of allergy. Although at present there is no cure for peanut allergy, previous studies have demonstrated that an allergy vaccine made up of a crude peanut protein extract could stimulate protective immunity but unfortunately also had an unacceptable rate of serious adverse allergic reactions. Researchers Bencharitiwong and colleagues report a novel approach to creating a hypoallergenic vaccine consisting of chemically modified peanut proteins that have the potential of retaining its beneficial immunizing properties while minimizing or eliminating its detrimental effects.

\section{Why did the Researchers do this Particular Study?}

Until recently, only few studies have addressed whether chemical modification of allergy vaccines could offer an effective strategy for adverse effect reduction in peanut allergy vaccines.

\section{Who or What was Proposed to be Studied?}

The researchers compared native and chemically modified crude peanut extracts in a test tube assay that measures the release of allergy-inducing chemicals from blood cells.

\section{How was the Study Done?}

The researchers compared chemically treated and crude peanut protein extracts with their ability to release allergy-inducing chemicals from blood cells of subjects with peanut allergy either in the presence or absence of sera (i.e., the liquid portion of the blood which contains antibodies). Chemical modification of the crude peanut protein extracts reduced the amount of allergy-inducing chemicals released from blood cells approximately by 100-fold lesser than quantities released by the untreated crude peanut preparations.

\section{What are the Limitations of the Proposed Study?}

The major limitation of the proposed study is that the authors' claims of reduced allergenicity as demonstrated by their in vitro (test tube) findings need to be verified in subsequent clinical studies in people with peanut allergy.

\section{What are the Implications of the Study?}

The results of the study suggest that the decreased allergenicity of the chemically modified crude peanut extracts may provide a basis for development of a safe vaccine for the treatment of peanut allergy. 